\title{
High Volume - High Value Usage of Flue Gas Desulfurization (FGD) By-Products in Underground Mines
}

\author{
Quarterly Report \\ October 1 - December 31, 1995
}

Work Performed Under Contract No.: DE-FC21-93MC30251

For

U.S. Department of Energy

Office of Fossil Energy

Federal Energy Technology Center

Morgantown Site

P.O. Box 880

Morgantown, West Virginia 26507-0880

By

University of Kentucky

Center for Applied Energy Research

3572 Iron Works Pike

Lexington, Kentucky 40511-8433

H) 


\section{DISCLAIMER}

Portions of this document may be illegible in electronic image products. Images are produced from the best available original document. 


\section{Disclaimer}

This report was prepared as an account of work sponsored by an agency of the United States Government. Neither the United States Government nor any agency thereof, nor any of their employees, makes any warranty, express or implied, or assumes any legal liability or responsibility for the accuracy, completeness, or usefulness of any information, apparatus, product, or process disclosed, or represents that its use would not infringe privately owned rights. Reference herein to any specific commercial product, process, or service by trade name, trademark, manufacturer, or otherwise does not necessarily constitute or imply its endorsement, recommendation, or favoring by the United States Government or any agency thereof. The views and opinions of authors expressed herein do not necessarily state or reflect those of the United States Government or any agency thereof. 


\title{
A High Volume--High Value Usage of Flue Gas Desulfurization (FGD) By-Products in Underground Mines
}

\author{
Cooperative Agreement No. DE-FC21-93MC30251
}

\section{Quarterly Report for the Period October 1, 1995 to December 31, 1995}

\section{Summary of Activity}

The amount of dry FGD materials produced in the U.S. has not been increasing at the high rate originally anticipated. This has been due to a number of economic factors affecting the utility industry. Technologies for the disposal of large amounts of materials are not going to be implemented in the near term. In light of this development the target application for this project is being changed from highwall adit filling to the filling of auger holes to allow for highwall mining. This application focuses on using the dry FGD material to recover coal isolated by excessive augering. It produces 10 or more times the amount of coal per ton of dry FGD utilized than the originally proposed methodology. It also does not require extensive equipment development and, if applied to abandoned mine lands, may have substantially more significant environmental benefit. We also propose to use a spray dryer material for the demonstration instead of the fluidized bed material originally proposed. The spray dryer material is already slacked eliminating problems associated with heat generation at the mine site. Auger hole grouting with FGD material is also best performed by hydraulic emplacement methods.

\section{Phase 1 Task 1, Laboratory and Economic Project Planning Project Focus Change: Filling of Auger Holes with FGD Material for Automated Highwall Mining}

Introduction During the program development over the past two years we have had some difficulty in finding suitable dry flue gas materials for the study. We have reached 
the conclusion that in the short term, i.e. the next 3 to 5 years, there will not be large quantities of dry FGD available for disposal.

There are a number of reasons for this. There is currently excess capacity and only a modest projected growth curve for increased power over the next few years. In addition, wet scrubbing systems have been substantially improved over time and fuel switching is also a viable option. Other major factors which slow the adoption of technologies which produce dry FGD are environmental regulatory uncertainties and, perhaps the single most significant factor, economic uncertainties due to the deregulation and subsequent corporate restructuring of American power generating utilities. Thus we have reached the conclusion that there will be little need for or interest in the methodology for the emplacement of large amounts of dry FGD materials, at least over the next few years, and some mid-project adjustments in our research strategy is worthwhile.

There are currently only 3 large lime feed spray dryers in operation and only a few utility sized (20 MW and larger) fluidized bed combustors operating in the U.S. Most of the approximately 180 AFBC's which are in operation are small industrial units. Many of the larger units are operating on coal cleaning wastes (culm or gob) by independent power producers (IPPs), but are still relatively small compared to utility generating units. There are no operational FBC's operated by the utilities in conventional service. We do expect the amount of dry FGD produced to increase as old generation stations are repowered

In the light of this conclusion we have shifted the target from filling highwall mining adits to filling auger holes with FGD material to provide a stable highwall for automated highwall mining. This application will require far less dry FGD material to be effective and will produce higher economic returns. There is also the potential for greater environmental benefit. 
Joy Technologies estimates that there are over 19,000 miles of abandoned highwall in Appalachian coal fields. They were created by old mining methods which consisted of contour-strip mining the coal and then auger-mining into the highwall 50 to 100 feet. These mines were then abandoned. Joy Technologies estimated that $25 \%$ of the abandoned highwalls are augered in this manner. The coal behind these short auger holes cannot currently be mined, and is commonly called "sterilized" or "shut in" coal. Assuming an average of 36 -inch thick seams this represents 2.8 billion tons of coal. Thus, this application has the ability to substantially contribute to America's coal resources.

Proposed Methodology The FGD material used in combination with automated highwall mining systems could reclaim this coal. The auger holes will be filled with FGD material. The expansive property of the FGD by-products, coupled with its strength, would reenforce the strata and allow automated highwall miners to cut back to the unaugered coal. The sterilized coal, which is often high quality, could then be recovered (Figure 1).

Auger hole grouting provides for higher levels of coal recovery compared to adit filling. Comparing auger hole grout application to highwall adit fill for the same coal seam geology clearly illustrates this difference (See Figures 2 and 3). A 1000 foot wide bench of 42 "thick coal which has been augured with a $36^{\prime \prime}$ inch diameter auger bit on a $48^{\prime \prime}$ center 75 feet through the coal seem would require a total of $5000 \mathrm{yd}^{3}$ of FGD grout to fill. If this bench was then highwall mined using conventional approaches, e.g. 11 foot wide adits with 4 feet of structural coal webbing between and every fifth adit left unmined, a total of $70,000 \mathrm{yd}^{3}$ of coal would be recovered and $54,400 \mathrm{yd}^{3}$ of coal would be left in the ground.

Using the FGD to fill the adits left by conventional highwall mining to recover the unmined coal would require substantially more FGD material. Let us assume a highwall mining situation where we left 11 foot webbing, filled these with FGD grout and 
Abandoned Augered

High Wall

Phase 1

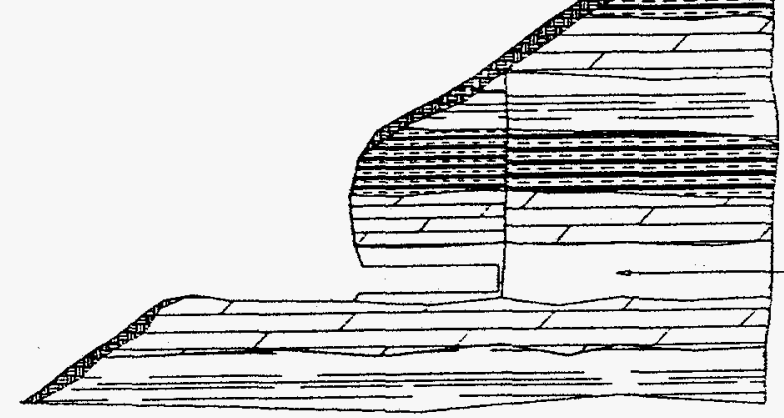

High Quality

Shut-in Coal

Pneumatic Emplacement of FGD Fill in

Old Auger Holes

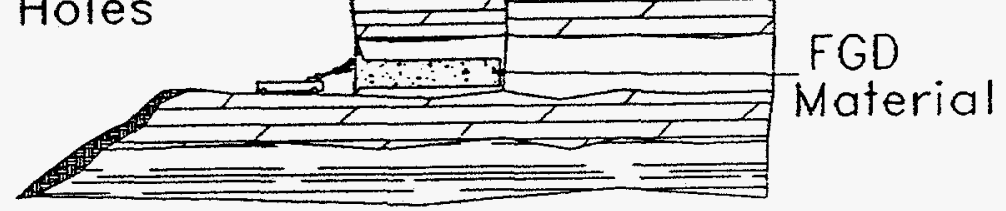

Phase 2

Highway Mine

Through FGD Fill

and Coal

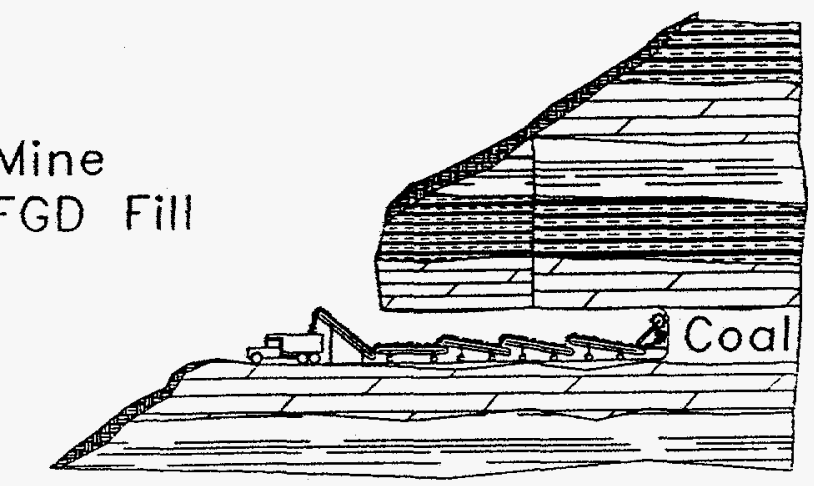

Phase 3

Reclaimed Mine

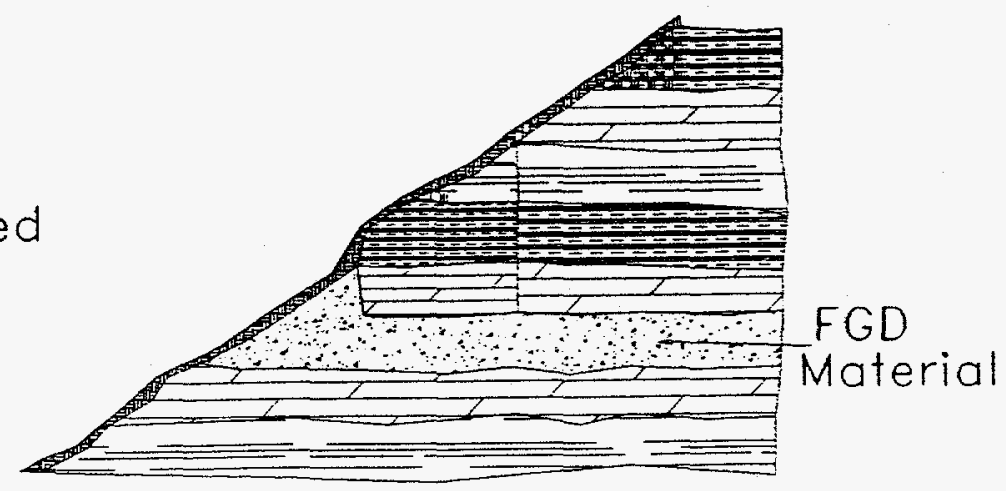

Figure 1. Schematic Diagram of Augered in Coal Recovery Using FGD Grouting Technology with Highwall Mining. 


\section{Present High-Wall Mine Adits Augered High-Wall Coal Seam}

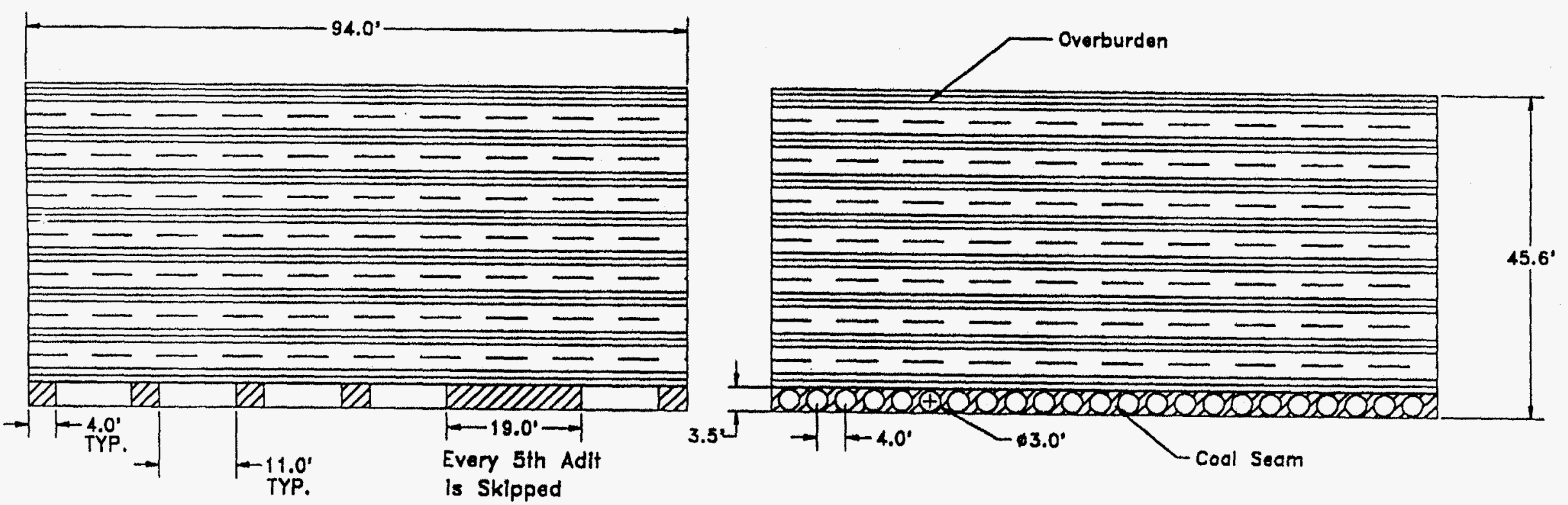

Figure 2. Face View Schematic Diagram Comparing Highwall Mined Coal Seam with Auger Mined Coal Seam. 
Plan View

Coal Remaining

Following Present

High-Wall Mining

Techniques

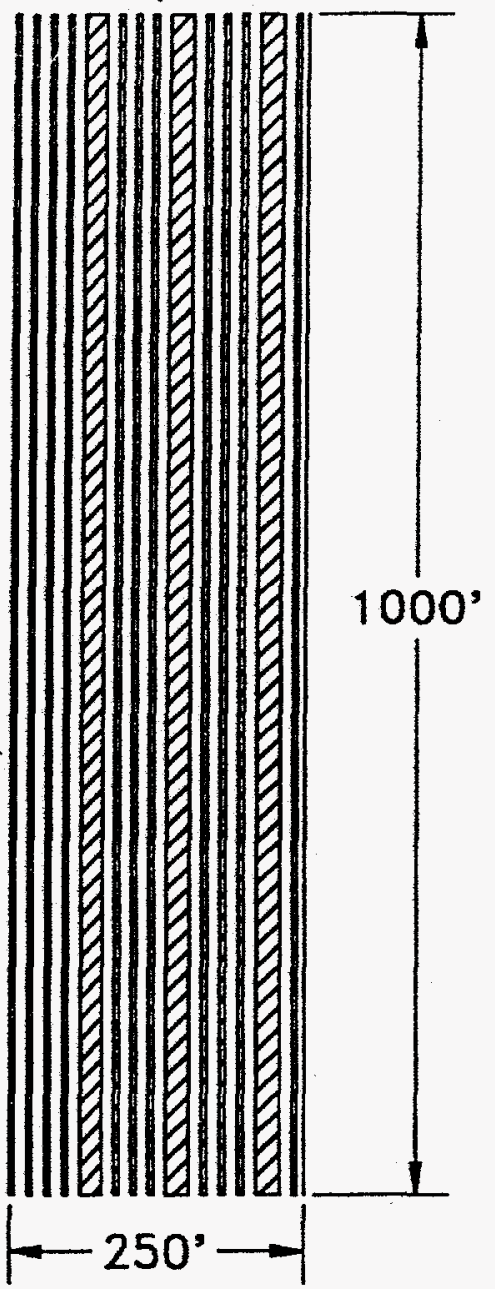

Elevation View

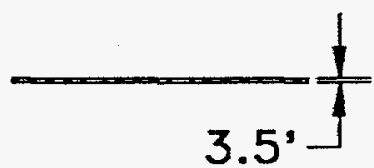

Notes: Hatched Areas Represent Unmined Coal Scale $=1^{\prime \prime}: 200^{\prime}$

Augered Coal

Seom Available

for High-Wall Mining

after FGD Grouting
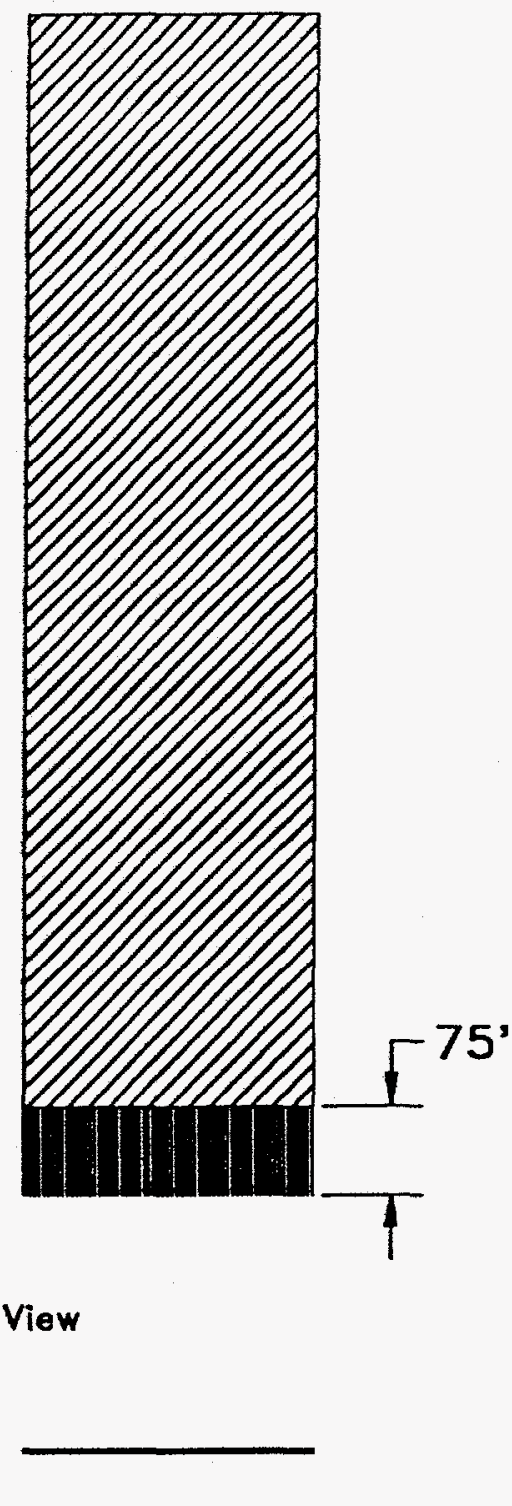
then recovered all of the remaining coal. In the this case, $64,200 \mathrm{yd}^{3}$ of FGD would be needed to recover this coal, or a ratio of $0.85 \mathrm{yd}^{3}$ of coal per $\mathrm{yd}^{3}$ of FGD fill used. Using the FGD material to fill in auger holes would result in $14 \mathrm{yd}^{3}$ of coal per $\mathrm{yd}^{3}$ of FGD grout used.

Concept Economics The auger hole fill case results in substantially better economic return. Assuming coal sells for $\$ 20 / y d^{3}$, the highwall adit fill would yield about $\$ 17$ worth of additional coal, while the auger fill scenario would yield about $\$ 280$ of additional coal. If we could get the FGD material onto the mine site for about $\$ 20$ /ton and premium coal is recovered, the cost of the fill may be as low as $7 \%$ to $10 \%$ of the value of the coal and the practice may be profitable.

The reclaiming of augured-in coal has been a puzzle for the coal industry for some time. It has been a topic of internal research at several coal companies. For example, Addington Resources studied the problem but found that the high cost of injecting conventional cement based concrete into the adits to be prohibitive (i.e. $30 \%$ to $50 \%$ of the value of the coal). Also we believe that the practice, if proven, could be of interest to mining service companies. In short, there are much better prospects for near term commercial development with this approach.

The development of new equipment would not be required for the auger hole grout application. Current cement pumping and handling technology will suffice to move materials the required 75 to 150 feet, although some small equipment modifications will probably be necessary to handle the FGD based slurry.

Environmental Benefit According to current mining regulations, when an area is remined it must be restored to current environmental standards. As these are much stricter than the mining practices of the 1950's and 1960's, this application could have a substantially positive environmental impact if it is used to reclaim old contour benches. 


\section{Subtask 2.1 Material Acquisition}

FGD Material to be Studied Fly ash from the Archer Daniel Midland (ADM) circulating fluidized bed combustion (CFBC) co-generation plant in Decatur, Illinois. has been studied most extensively in this project to date. There are a couple of factors, however, which have persuaded us to switch to another material for the mine demonstration. First, the ADM material has a high free-lime $(\mathrm{CaO})$ content which produces large amounts of heat upon hydration. Dealing with this hydration reaction at the mine site would require an additional processing step. In addition, the heat of hydration could possibly ignite the coal seam or cause a steam explosion if the reactions continued to a significant extent underground. Second, Freeman United Mining Co. disposes of the FGD material at its Crown III facility in Farmersville, Illinois which is approximately 500 miles from the coal fields of eastern Kentucky. Transport of this material to the mine demonstration in eastern Kentucky is feasible for the project but would diminish resources which could otherwise be used for research.

It is proposed that spray-dryer by-products which are currently handled by Costain be used for the mine demonstration instead of the ADM material. This material is currently being railed to the Costain mine in Pike County, Kentucky as part of the coal contract between Costain and U.S. Generating. Therefore, this material will be readily available in the coalfield district of eastern Kentucky where the mine demonstration will take place. In addition, the spray dryer material does not contain significant amounts of free lime, which simplifies the grouting process because there is no significant heat dissipation required. The disadvantage of using this material is that an additional round of formulation testing will be required to establish the optimum water content for strength development. The testing of fly ash admixtures is also planned. By utilizing our experience with testing of the ADM material, the test program for the spray dryer material will be significantly streamlined and shortened. The hydraulic method of emplacement that will be proposed in the following sections will likely require rheology testing of the FGD slurry/paste prior to curing. 


\section{Mine Demonstration of Auger Hole Grouting}

Task 4.0 Background for Phase II

Subtask 4.1 Mine Selection

Mine Site Requirements

The selection of a superior mine site is essential for the successful demonstration of FGD auger hole grouting. While there are literally thousands of miles of coal seams that have been sterilized to highwall mining by augering, only a small fraction of these sites are likely to be suitable for a demonstration of this concept at this early stage of development. Both monetary and technological constraints will require that easily accessible and well preserved auger holes be initially tested for FGD grouting. Many abandoned mines may be simply inaccessible without substantial road building, and many augered coal seams have undoubtedly experienced serious fracturing and subsidence over the years. As the technology for this backfill concept matures, techniques for filling these more difficult types of auger holes will likely be developed. However, the scope of the current project requires that the best possible site be identified to ensure the success of the mine demonstration. Following are a list of the requirements that we will seek in selecting a mine demonstration site.

- An augered coal seam of at least 3.5-ft thickness that has at least $1000 \mathrm{ft}$ of recoverable shut-in coal. (The coal seam must be suitable for subsequent highwall mining).

- Good overburden strata (preferably sandstone) for the safety of workers on the bench and for reduced risk to underground equipment. (No workers will enter the auger holes). 
- Approximately 10 auger holes (3-ft diameter) that occur at a 4-ft pitch. The holes should be 75 to $100 \mathrm{ft}$ long and should not intersect. They should be relatively uniform in shape, unobstructed for the entire length, and should not contain significant amounts of spalled coal on the floor. It would be ideal for the coal seam to be slightly dipping. The holes should contain minimal water.

- The demonstration should be placed so that subsequent study of the FGD material following placement may be possible.

- Assistance from the mining company at the site is essential for the preparation of the bench and for incidental utility and heavy equipment support. It would be ideal for the mining company to mine a portion of the grouted auger holes so that the physical and chemical characteristics of the FGD grout may be ascertained.

\section{Subtask 4.2 Selection and Testing of Transport System}

\section{FGD Grout Emplacement Technology for the Mine Demonstration}

In the haulback scenario that was originally emphasized in this program, large 11- $\mathrm{ft}$ wide highwall adits were to be filled completely with FGD cement. Because it was essential for the re-mining concept that the FGD cement support the roof of the adit, shotcreting technology was selected for utilization because of its precise emplacement characteristics. It is possible with shotcreting (pneumatic emplacement) to coat vertical and overhead surfaces, and thus, it is commonly used, especially in Europe, for lining large underground tunnels. The disadvantages of shotcreting are that it is dusty, it is not commonly used for bulk-fill applications, and it requires a skilled operator to direct the emplacement of the cement. 
With the emphasis of the program changing to auger hole grouting instead of filling highwall mine adits, the selection of the emplacement technology for the mine demonstration has been re-evaluated. Shotcreting is not considered to be a viable option for grouting auger holes because of their small diameter. In shotcreting, a turbulent jet of air is used to mix water and solids within a nozzle at the end of a pipe and to transport the mixture onto a surface normal to the jet. Ideally, the water-solids mixture sticks to the surface and air exits parallel to surface. However, there are always some liquid and solid particles which remain airborn and are not collected on the surface. For outdoor surfaces and large interior surfaces where the dusty air can escape normal to the shotcrete jet, the vision of the nozzle operator is generally not impeded. However, when shotcreting into corners or into small enclosures, the fugitive dust is forced to travel backward, parallel to the oncoming stream of shotcrete. The complex air flow patterns produced by impact of the turbulent jet with non-normal surfaces not only obscures the vision of the nozzle operator but it also produces poor results.

Initial laboratory-scale shotcreting tests at the CAER were performed by using, as the collector for the FGD cement, a 55-gal drum laid on its side. Dust billowed out of the drum which was so thick that it was impossible to see inside the drum to adjust the position of the nozzle. The result was that a series of horizontal cones of FGD cement repeatedly formed on the back of the drum and then broke off. Testing was then changed so that the collector was a flat wooden surface that would permit dust to escape normal to the oncoming shotcrete stream. These tests were much more successful because the dust did not obscure the vision of the operator and it was possible to evenly apply the FGD cement. It is believed that the 11-ft wide highwall adit would have provided sufficient space to promote dust dissipation and to permit a remote vision system to function. It was concluded, however, that shotcreting within a much smaller confined space like auger holes would not be viable because positioning the nozzle to evenly apply the FGD cement would be impossible. 
With the rejection of the pneumatic emplacement method for the revised mine demonstration, hydraulic emplacement was re-considered for utilization. Hydraulic emplacement was not chosen for the original plan because of concerns about slump and with scale formation inside transport piping of greater than $1000 \mathrm{ft}$. To fill the wide highwall mine adits completely, it was determined that forms (either stationary or mobile) would be necessary to retard slump and permit the void to be completely filled to the ceiling. It was believed that remote placement of forms would be difficult and the results would be less effective than shotcreting. For the revised backfill plan, however, the pumping distances are much shorter $(\sim 100 \mathrm{ft})$ and the cross-sectional area is much smaller, which makes hydraulic emplacement (grouting) more attractive. A disadvantage of the shotcreting concept was the need for a remote vision system; pressure grouting can be monitored and controlled more simply by recording the pressure at the outlet of the grouting pipe.

Although the auger holes are potentially less challenging to backfill than highwall adits because of the size difference, it remains crucial that the FGD cement fill the voids sufficiently to support the roof during remining with a highwall miner. Therefore, the grouting technique that is used must reduce slumping in order to be effective. Two basic strategies for filling the auger holes will be explored. One is to pump the FGD grout deep into the hole with either stationary or moving piping (Figures $4 a, 4 b$, and 4c). The other scenario is to dam the face of the hole and then pour FGD-based flowable fill into the void near the face without pumping (Figure 4d). Discussions with concrete equipment suppliers and contractors will be held in order to evaluate the best the method for the mine demonstration and for the economic evaluation. The best method for the mine demonstration may not be best suited for commercial development. 
o) Grouting with Low-Slump FGO/Fly Ash Coment
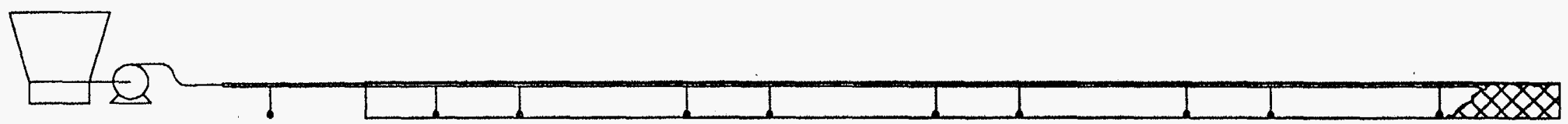

b) Pressurs Grouling with Moving Bulkhood

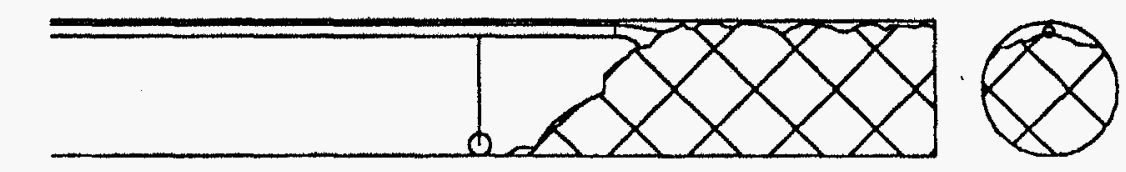

$\longrightarrow$
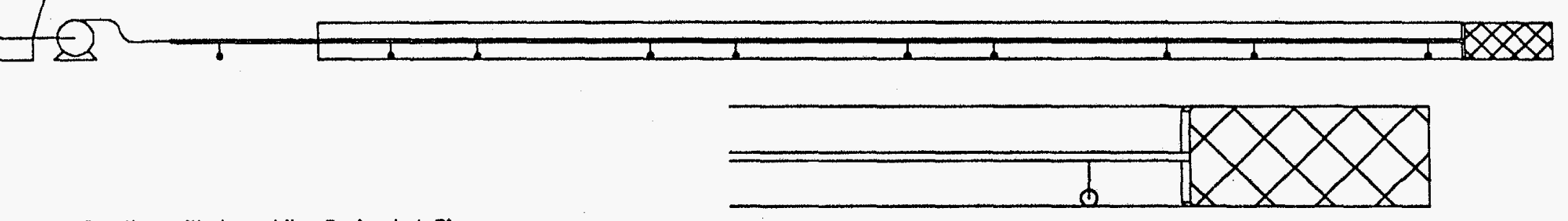

c) Pressure Grouting with Immoblle, Perforated Pipe

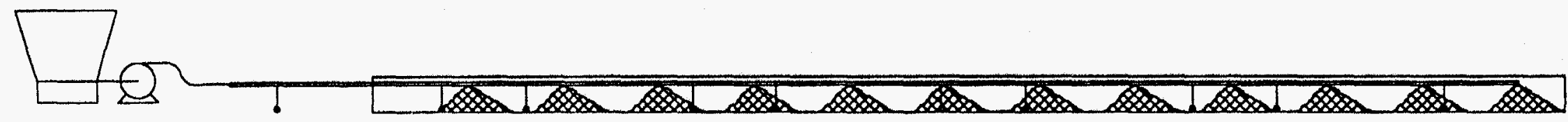

d) Flowable Fill of Foce w/o Pumping

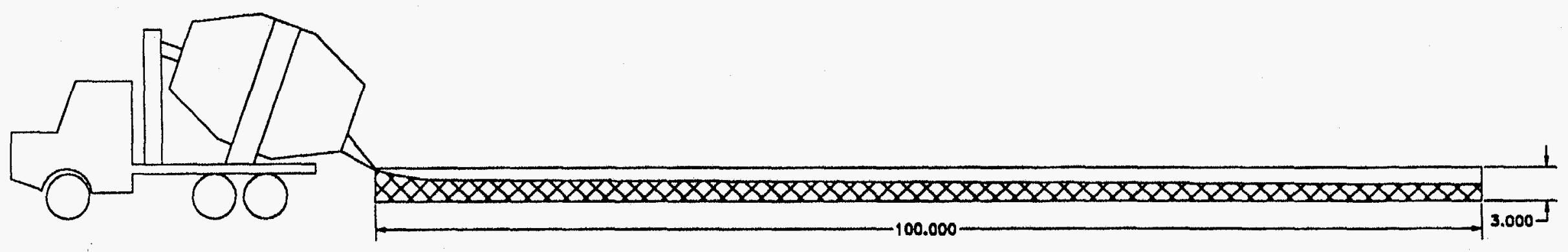

Figure 4. Schematic Diagram of Grout Emplacement Methodologies. 


\section{FGD Grout Pumping}

Two pumping scenarios are presented here that include the retraction of the feed pipe as the FGD cement is emplaced. Another possibility is that the feed pipe could be buried in the FGD grout as emplacement proceeds and not recovered. While the latter scenario is not likely to be implemented commercially, it may be a useful technique for the mine demonstration.

a) Grouting with Low Slump FGD/Fly Ash Cement. In this scenario the feed pipe would be positioned near the roof of the auger hole and FGD cement would be pumped to the end of the pipe. In order for this technique to work the FGD slurry must have relatively little slump so that the material can be stacked nearly to the ceiling. The rate of retraction of the feed pipe may be controlled by monitoring the pressure at the outlet of the pipe. When the pressure increases it may be assumed that the leading edge of the FGD cement is encroaching on the end of the pipe. Monitoring this process with a remote camera during the mine demonstration would be useful, but commercial operation would not require such monitoring. While this is possibly the simplest pumping technique, it will probably give the worst results in terms of filling the hole to the ceiling.

\section{b) Pressure Grouting with Moving Bulkhead. This technique would potentially} give the best results because the FGD cement would be pressurized behind the bulkhead effectively eliminating air voids. The bulkhead would then move when a certain pressure was obtained behind the bulkhead. This sort of technology is currently used for tunnel lining. However, irregular openings may limit the widespread use of this technique. In addition, the development of a bulkhead device may be beyond the scope of this project.

c) Pressure Grouting with Immobile, Perforated Pipe. This method may be useful only for the mine demonstration because it is probably not economically feasible 
to leave behind pipe in each auger hole that is filled. If the grouted auger holes were remined then it would be necessary to use plastic piping to prevent damage to the miner. By injecting FGD cement at several points in the auger hole with perforated pipe, it is expected that the ceiling would be supported by the grout at several points along the hole, if not the entire length. The obvious concern about this technique is that the pipe may become clogged near the face of the auger hole during the initial phase of the operation and prevent the filling of the remainder of the hole. The buried pipe would provide opportunities for post-emplacement studies. It would be possible shortly after emplacement to clear the pipe of FGD grout while it is relatively soft. The pipe would then provide access for various probes, and it would also allow collection of leachate.

\section{FGD Flowable Fill}

The use of concrete pumps usually increases the cost of concrete substantially compared to applications where gravity-fed pouring is used. Therefore, there is a possible economic advantage for formulating an FGD-based flowable fill material to eliminate the need for pumping. The disadvantage of this method is that fill to the ceiling would not be possible except at the entrance. Unless an extremely flowable mixture is formulated, the fill may not reach the end of the auger hole at all. Moreover, for coal seams that incline, even slightly, a flowable fill method would not be suitable. Rheology testing for this type of material is essential.

\section{Rheology of Spray Dryer/Fly Ash Slurries and Pastes For all of the hydraulic} emplacement methods that were discussed, knowledge of the rheological characteristics of the various slurry admixtures is essential. This type of information was not critical when pneumatic emplacement was the envisioned emplacement technique because transport was to be performed while dry. It is proposed that a series of tests be conducted in parallel to the strength and physical characterization tests to measure the slump, flow, and viscosity of the materials. These tests in 
conjunction with the strength testing will help guide our decision on the best emplacement technique for the mine demonstration. 